\title{
EDITORIAL
}

\section{Are radiologists true medical imaging gatekeepers?}

Sanjay N Jain

Editor-in-Chief, The Indian Journal of Radiology and Imaging, Department of Radiology, Prince Aly Khan Hospital, Mazagaon, Mumbai, Maharashtra, India. E-mail: editor@ijri.org

\section{Dear Colleagues,}

When I asked myself as to what do I write as the subject for the editorial pertaining to the November 2014 issue of the journal; I looked around; spoke to colleagues and friends, brain stormed and delved within to see what could be an apt topic. It had to be something which has defined and recognized us radiologist - the medical imaging specialists, from the genesis of radiology till now, and from here on, how would this definition hold good as we walk forward. As I was pondering over this point, intriguingly, with my eyes shut, on the chair, my inner voice said the basis of my recognition as a radiologist comes from the specialty of radiology to which I belong to; it takes care of my bread and butter. The way I'm taken care of and which recognizes me as an expert in imaging and radiology, germinated a thought of how well am I taking care of our profession, as a primal requirement, and not as a reciprocatory gesture. Radiology cannot speak for itself; it speaks through the radiologist. The utility of a knife is known based on how a person wants it, as the knife can't speak for itself. To speak for radiology, we need to be its guardian, by protecting the profession from coming into the grip of areas other than those intended to be used for. Thus, what came in from me was the aspect of the gate keeper of radiology that we are supposed to be-are we really into it?

Just for reasons of understanding, gatekeeper is known as one who is a caretaker or custodian. If we use the phrase as a very reference here, it means that we are expected to be the gatekeepers of radiology, which goes on to ensure that we do our best in making the flag of radiology fly high, at the back drop of the challenges; guidelines put forth by regulatory bodies, along with social acceptance and approval. Social standing in the sense that, at the end of the day, the modalities of radiological imagery are for

\begin{tabular}{|c|c|}
\hline \multicolumn{2}{|c|}{ Access this article online } \\
\hline Quick Response Code: & \multirow[b]{2}{*}{$\begin{array}{l}\text { Website: } \\
\text { www.ijri.org }\end{array}$} \\
\hline & \\
\hline 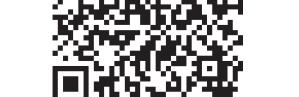 & $\begin{array}{l}\text { DOI: } \\
\text { 10.4103/0971-3026.143892 }\end{array}$ \\
\hline
\end{tabular}

the common man in the society. Anything that the society feels good about; as part of its well-being; would be directly proportional to the acceptance, recognition, and furtherance of radiology; though, with adequate financial consideration. On one hand, as we deal with newer technologies to adapt, suiting our requirement, on the other, ethical considerations and utilizing the available logistics at our disposal, within the fetters of the profession, consciously strives us in playing this balancing act. ${ }^{[1]}$ Hence, it is time for a SWOT (strengths, weaknesses, opportunities, and threats) analysis for each radiologist, to focus based on his or her strength with the imaging modality in the quest for the opportunities to be explored, and to understand the situational weakness which could direct one towards a threat.

Gate keeping, in its truest sense, looks upon to ensure that the overall health of radiology is always intact. Negatives override positives in a fraction of a second. It is warranted to look into the element of commoditization of medical imaging, by virtue of needless tests and procedures, with piling costs, often resulting in the arena of nowhere, just as in an open space of cosmos, without any conclusion to be arrived at by using a particular imaging technique. A technique used justifiably for the heck of it or with an ulterior motive. The radiologist needs to look into, on reference from a referring physician or a surgeon, as to whether a said modality-based imaging is warranted or can it be done through a lesser medium, most suitable to the requirements of the case. ${ }^{[2]}$ As the adage goes, it is always patient first; unless and until patients are referred to, how will the machinery be used and the inferred upon. Access to any technology can be possible, provided it is affordable by the patients. Primarily, the first point of testing needs to be, by and large possible, the last point of testing as well. While all this is being probed into, the most pertinent aspect would be never to compromise on quality in trying to cut down the cost factor, but, needs to be made affordable. Many patients shy away from undergoing a test, for the mere fear of the money involved, and what if nothing comes out, as it is purported to be. The radiologist, always, needs to convince himself or herself, as regards the necessity of an image to be taken, as requested by the physician; instead, if he or she feels that it isn't warranted and something lesser could reap the required benefit, the same needs to be communicated to the referring physician 
or surgeon. Active imaging, rather than passive, needs to be witnessed here, as we are not here just to perform an imaging technique and churn out images, viewing the same as an assistive mechanism to the physicians, but, as an advisor, inferring based on the image taken. As part of the inferring mechanism, in required cases, the patient also needs to be informed about the inference, if need be, over and above the report sent to the referring physician. ${ }^{[3]}$

As in x-ray and related imaging modalities, the need to take more number of images would primarily risk the patient be exposed to unwanted radiation, leading to healthcare complications thereof, whereby, making the radiologist accountable for any mishap, over and above what is warranted to be imaged. This is as good as a surgical complication, though, the consent form from the patient's relatives are taken before surgery, as a dictum, with complications contemplable, but, error on part of the surgeon cannot be overruled, leading to patient fatality at times, though, that may not be the intention. So is the case in some procedures which are under the gamut of interventional radiology and neuroradiology, respectively. In pursuit of making radiology a good money-making specialty, the core area of focus is patient care should not be forgotten.

One of the principle challenges which we face in India vis-a-vis the West, is the federal healthcare providing society the access to best medical facilities, which is also mandatory; but, we are well behind in pursuit of enacting such a law. One reason could be the huge population base which we have, in sharp contrast to lesser number of people in the West. A true reflection of gatekeeping would be made possible, provided the education of departmental colleagues, staff, residents, students, patients, etc., is also incorporated. Many of the laws and rules applicable to the West cannot be applied in India, which proves to be a deterrent to practical applications of social benefit.

The ever evolving challenge which we face from time to time, especially, when newer imaging machinery is pressed into service, is how to recover the cost of installation, as these high-end imaging machines are very expensive and it would take some time before the break even can be achieved. A facet of gatekeeping from radiologist's perspective, is to minimize cost to patients for imaging, but, at the same time, the heavy burden of capital expenditure of acquiring such an equipment needs to be vouched for in the path of adequately monetizing the image services.

Not only that, another major area which is slowly, but steadily, creeping in, though not at the immediate, but, still needs to be looked into, is picture archiving and communication system (PACS), which is storing of imagery in a PACS equipment, in Digital Imaging and Communications in Medicine (DICOM) format, that can be viewed transcending geographical boundaries in a very short span of time. This technology is very much in vogue in the West, where in countries like USA, the Food and Drug Administration (FDA) regulates the PACS as a classified medical device, which is quiet contrast in India, where such a system does not exist; as each institution has its own database of images and records, barring few major academic institutes.

Finally, looking at all the above, the need of the hour is to figure out what is best suited for Indian conditions, unlike merely aping the western technology and practices, wherein, the logistics of implementation are quite different. Effective balance of technology, cost-cutting, alongside commodizition, and misuse of the equipment leading to medicolegal issues would be the principle responsibilities of we gatekeepers, and as we delve through these, we come back to the basics of taking care of the radiology, in the best possible manner, since, unless there is the radiology, how would we radiologists eat our bread and butter? A radiologist can never exist without radiology; a point to eternally pondered upon.

In pursuit of offering dedicated scientific knowledge to our learned members, with colleagues acting as Guest Editors to dedicated issues, we have "Transplant Imaging" in this issue, which is being edited by Dr. Nitin Ghonge. The issue features leading contributors from India and abroad, with the latest concepts. Organ transplantation is undergoing seismic changes in the country, with radiological involvement becoming an integral component in the pre- and post-procedural scenario.

Please keep writing to me on the areas of interest that you would like to concentrate upon, IJRI would delve into them, by bringing in newer articles, from edition to edition.

\section{References}

1. Jha S. From imaging gatekeeper to service provider-a transatlantic journey. N Engl J Med 2013;369:5-7.

2. Hurley R. Can doctors reduce harmful medical overuse worldwide? BMJ 2014;349:g4289.

3. Available from: http://www.radiologybusiness.com/topics/ business/radiologist-gatekeeper-part-i?nopaging=1 [Last accessed on 2014 Sep 30].

Cite this article as: Jain $\mathrm{SN}$. Are radiologists true medical imaging gatekeepers?. Indian J Radiol Imaging 2014;24:315-6. 